\title{
Los mecanismos organizativos de las prácticas económicas alternativas en las ciudades españolas
}

\author{
José Luis Sánchez Hernández \\ Universidad de Salamanca. Departamento de Geografía \\ jlsh@usal.es
}

\section{Resumen}

Las prácticas económicas alternativas son formas comunitarias de coordinación económica que intentan resolver el problema de la asignación de los recursos escasos mediante la cooperación y la reciprocidad entre los actores implicados en la provisión de bienes y servicios. Este artículo estudia las soluciones organizativas que caracterizan a estas economías alternativas. Para una muestra de 67 casos localizados en ocho ciudades españolas, se ha recogido información individualizada sobre nueve variables: forma jurídica, propiedad de los recursos, vías de financiación, formas de retribución del trabajo, modalidad de acceso al mercado (para productores), modalidad de acceso al bien/servicio (para consumidores), medio de pago, sede y escala geográfica de actuación. Los resultados demuestran el predominio de determinados mecanismos organizativos que dibujan el perfil distintivo de estas prácticas alternativas. Sin embargo, también se ha detectado la presencia de ciertos rasgos de índole capitalista que demuestran la diversidad interna del mundo de las economías críticas.

Palabras clave: prácticas económicas alternativas; reciprocidad; formas de organización; ciudad; España 
Resum. Els mecanismes organitzatius de les pràctiques econòmiques alternatives a les ciutats espanyoles

Les pràctiques econòmiques alternatives són formes comunitàries de coordinació econòmica que intenten resoldre el problema de l'assignació dels recursos escassos mitjançant la cooperació i la reciprocitat entre els actors implicats en la provisió de béns i serveis. Aquest article estudia les solucions organitzatives que caracteritzen aquestes economies alternatives. Per a una mostra de 67 casos localitzats en nou ciutats espanyoles, s'ha recollit informació individualitzada sobre vuit variables: forma jurídica, propietat dels recursos, vies de finançament, formes de retribució del treball, modalitat d'accés al mercat (per a productors), modalitat d'accés al bé/servei (per a consumidors), mitjà de pagament, seu i escala geogràfica d'actuació. Els resultats demostren el predomini de determinats mecanismes organitzatius que dibuixen el perfil distintiu d'aquestes pràctiques alternatives. No obstant això, també s'ha detectat la presència de certs trets d'índole capitalista que demostren la diversitat interna del món de les economies crítiques.

Paraules clau: pràctiques econòmiques alternatives; reciprocitat; formes d'organització; ciutat; Espanya

Résumé. Les mécanismes d'organisation des pratiques économiques alternatives dans les villes espagnoles

Les pratiques économiques alternatives sont des formes de coordination économique basées sur la communauté qui tentent de résoudre le problème de l'allocation de ressources rares par la coopération et la réciprocité entre les acteurs impliqués dans la fourniture de biens et de services. Cet article étudie les solutions organisationnelles qui caractérisent ces économies alternatives. Pour un échantillon de 67 cas situés dans huit villes espagnoles, des informations individualisées ont été recueillies sur neuf variables : forme juridique, propriété des ressources, modes de financement, formes de rémunération du travail, mode d'accès au marché (pour les producteurs), mode d'accès au bien/service (pour les consommateurs), moyens de paiement, siège et échelle géographique de l'action. Les résultats montrent la prédominance de certains mécanismes organisationnels qui dessinent le profil distinctif de ces pratiques alternatives. Toutefois, la présence de certains traits de nature capitaliste a également été détectée, ce qui démontre la diversité interne du monde des économies critiques.

Mots-clés : pratiques économiques alternatives; réciprocité; formes d'organisation ; ville ; Espagne

\section{Abstract. Organizational mechanisms of alternative economic practices in Spanish cities}

Alternative economic practices are community-based forms of economic coordination that seek to solve the problem of the allocation of scarce resources through cooperation and reciprocity between all actors involved in the provision of goods and services. This article studies the organizational schemes particular to these alternative economies. Using a sample of 67 cases from eight Spanish cities, individualized information has been collected on nine variables: legal form, ownership of resources, funding procedures, forms of labor remuneration, mode of market access (for producers), mode of access to the good/service (for consumers), means of payment, headquarters, and geographical scale of action. The results demonstrate the predominance of certain organizational mechanisms that mark the distinctive profile of these alternative practices. However, there has also been a presence of certain capitalist traits; a key factor that highlights the internal diversity of the world of critical economies.

Keywords: alternative economic practices; reciprocity; organizational schemes; city; Spain 


\section{Sumario}

\author{
1. Introducción y objetivos \\ 2. Las modulaciones de la economía \\ alternativa: una revisión \\ 3. Metodología de investigación \\ 4. Resultados: unidad y diversidad \\ organizativa de las prácticas económicas \\ alternativas \\ 5. Conclusiones: una lectura geográfica \\ de las economías alternativas \\ Referencias bibliográficas
}

\section{Introducción y objetivos}

La crisis económica, social y política desencadenada en 2008 por el estallido de la burbuja inmobiliario-financiera reabrió el debate sobre la capacidad del capitalismo para construir un modelo económico que, además de eficiente, sea inclusivo, sostenible y democrático. Este debate no es nuevo, puesto que la crítica al capitalismo nació con el capitalismo mismo, pero se había acallado con su práctica universalización tras la reforma china de 1978 y la implosión del socialismo real en 1989. La tesis de Francis Fukuyama sobre un «fin de la historia» encarnado en la doble hegemonía global de la democracia parlamentaria y el capitalismo neoliberal encontró cierto respaldo empírico en la etapa de crecimiento económico que concluyó con la quiebra de Lehman Brothers en 2008. En estos años, se llegó a hablar del final de los ciclos económicos, pese a la crisis financiera asiática de 1997 o al desplome bursátil de las empresas de internet en 2001.

Como recuerda Estefanía (2020), las llamadas a la «refundación del capitalismo» tras 2008 tuvieron tanto eco mediático como escaso efecto real. Serán los graves efectos sociales de las políticas de consolidación fiscal (Streeck, 2017), el auge de partidos políticos extremistas (Rodríguez-Pose, 2018) y la concienciación sobre la amenaza de un cambio climático "capitalogénico" (Cózar, 2019) los factores que justifican la actual eclosión de propuestas para reformar el capitalismo desde dentro.

Cabe citar aquí a Branko Milanovic (2020) y su "capitalismo popular», a Joseph Stiglitz (2020) y su "capitalismo progresista» o a Thomas Piketty (2019) y su «socialismo participativo». En 2020, la Cumbre de Davos (Schwab, 2019a; 2019b) suscribió el llamamiento de la Berkeley Roundtable (2019) para construir un "capitalismo de las partes implicadas» o «stakeholder capitalism». Según este influyente foro económico estadounidense, las empresas no deben limitarse a maximizar los beneficios de sus propietarios, sino que deben contribuir a la prosperidad de sus comunidades a través de una gestión responsable, unas condiciones laborales dignas y una relación colaborativa con sus proveedores y clientes.

Estas reflexiones internas al capitalismo oficial representan la expresión visible de una corriente crítica más profunda que no se contenta con la denuncia mediática y la confrontación dialéctica. Al contrario, se plasma en acciones concretas que intentan construir modelos alternativos al capitalismo financie- 
ro globalizado. Chaves y Monzón (2018) gradúan tales alternativas en función de su formalización jurídica y su incorporación a la praxis empresarial: «economía social», «innovación social», «economía colaborativa», «economía circular», «responsabilidad social empresarial», «economía del bien común», «empresa/empresariado social», «economía social y solidaria» y «economías transformadoras». Con este último adjetivo, los autores se refieren explícitamente a las "prácticas económicas alternativas», que Sánchez y Moro (2019: 112) definen así:

Mecanismos de coordinación económica que se rigen por principios de autonomía, reciprocidad y democracia directa, promueven valores no competitivos (sostenibilidad, cooperación, equidad) y pretenden eliminar, transformar o superar la variedad de capitalismo hegemónica en su marco geográfico de actuación.

Se trata de propuestas con un decidido carácter político, impulsadas por colectivos ciudadanos que promueven una economía orientada a la satisfacción de las necesidades humanas básicas. Caben aquí los espacios autogestionados, los movimientos campesinos agroecológicos, las comunidades virtuales de expertos digitales, las experiencias de cohabitación, las tiendas gratuitas, las divisas locales, las redes de trueque o los comedores comunitarios, entre muchas otras iniciativas.

Todas ellas colocan en el centro de su ideario las nociones de la comunidad como sujeto de la acción económica y de la cooperación como principio de coordinación, frente al individuo y la competencia que definen el núcleo de la economía capitalista. Sin embargo, algunas investigaciones (Conill et al., 2012; Sánchez, 2019b) sugieren que el mundo de las economías alternativas es muy diverso en cuanto a tamaños, objetivos, ámbitos de acción, escalas de trabajo, modalidades organizativas o articulación con el capitalismo y con la Administración.

No debería usarse, pues, un lenguaje binario que solo distingue entre $e l$ capitalismo y la alternativa. Ambos albergan modulaciones temporales, geográficas e institucionales que, al menos para el caso de las alternativas, no han sido objeto de atención suficiente por parte de la Geografía Económica.

Este artículo asume esa concepción fluida o gradualista y pretende contribuir al conocimiento de las soluciones organizativas que adoptan las prácticas económicas alternativas (PEA) a partir del estudio de 67 casos localizados en ocho ciudades españolas. Los resultados demuestran que la reciente difusión de tales prácticas en España se ha construido alrededor de un núcleo común de valores y procedimientos, expresados en un perfil organizativo mayoritario. Ahora bien, la centralidad de dicho perfil no ha impedido el desarrollo de una apreciable variedad de mecanismos de funcionamiento, incluidos algunos de tinte capitalista. El resultado final es una pluralidad de formatos alternativos cuyo análisis abordan las siguientes preguntas de investigación: 
- ¿Qué recursos materiales se emplean en la construcción de las PEA?

- ¿En qué aspectos concretos difieren los recursos movilizados por las PEA de los que emplean las empresas convencionales?

- ¿Existe un modelo único de combinación de dichos recursos materiales por parte de las PEA o se observa una diversidad de soluciones organizativas en el ámbito alternativo?

- ¿Cuáles son las implicaciones de esta diversidad sobre la capacidad de las PEA para transformar el sistema socioeconómico hegemónico?

El artículo se estructura en cuatro partes. La primera combina la literatura que ha destacado la diversidad interna de la economía con la que analiza las alternativas al capitalismo. Esta combinación es necesaria para construir, en la segunda parte, una metodología capaz de captar dicha diversidad. La tercera expone los resultados obtenidos mediante la aplicación de esa metodología y discute la naturaleza transformadora de las PEA a la luz del doble marco teórico. Las conclusiones sintetizan las principales aportaciones teóricas y empíricas del trabajo.

\section{Las modulaciones de la economía alternativa: una revisión}

La diversidad de las economías alternativas no puede comprenderse sin un examen previo de la variedad de recursos y formas de organización que puede adoptar la economía, entendida de manera extensa como un proceso social orientado a cubrir las necesidades materiales humanas. La aportación más minuciosa y conocida a este respecto corresponde a J. K. Gibson-Graham (2014, tabla 1). Para los cinco elementos esenciales de todo sistema económico (empresa, trabajo, propiedad, intercambio y financiación), se agrupan las soluciones histórica y empíricamente observables bajo tres formas de coordinación. La fila superior muestra las soluciones de mercado dominantes en las economías capitalistas. La fila intermedia incluye relaciones coordinadas por distintas formas de mercado y protagonizadas por actores que procuran compaginar sus objetivos particulares con el servicio a la comunidad. En la fila inferior aparecen las soluciones habitualmente ignoradas por la ciencia económica ortodoxa, pese a que muchas de ellas proporcionan bienes esenciales para el bienestar colectivo, como los cuidados.

White y Williams (2016, tabla 2) profundizan en la diversidad real de las formas de trabajo que operan en las sociedades capitalistas mediante una tipología que cruza dos variables: la forma de retribución (monetaria/no monetaria) y el espacio económico donde se trabaja (hogar, comunidad, sector informal, sector público y sector privado). Resultan diez posibilidades que se entrelazan en la vida cotidiana y abarcan la totalidad del «trabajo social»: una misma persona, en un único día laborable, puede desarrollar tareas domésticas no retribuidas, colaborar en una asociación sin ánimo de lucro, trabajar legalmente a cambio de un salario y extender su jornada laboral más allá del horario retribuido sin percibir por ello un ingreso adicional. 
Tabla 1. La diversidad de las economías según Gibson-Graham

\begin{tabular}{|c|c|c|c|c|}
\hline Empresa & Trabajo & Propiedad & Intercambio & Financiación \\
\hline Capitalista & Remuneración salarial & Privada & Mercado & Mercado dominante \\
\hline $\begin{array}{l}\text { - Empresa familiar } \\
\text { - Empresa privada } \\
\text { - Empresa pública } \\
\text { - Multinacional }\end{array}$ & $\begin{array}{l}\text { - Asalariado } \\
\text { - Sindicado } \\
\text { - No sindicado } \\
\text { - Tiempo parcial } \\
\text { - Eventual }\end{array}$ & $\begin{array}{l}\text { - Propiedad individual } \\
\text { - Propiedad colectiva }\end{array}$ & $\begin{array}{l}\text { - Libre } \\
\text { - Bajo protección natural } \\
\text { - Bajo protección artificial } \\
\text { - Monopolio } \\
\text { - Mercado regulado } \\
\text { - Nicho }\end{array}$ & $\begin{array}{l}\text { - Banca privada } \\
\text { - Aseguradoras } \\
\text { - Servicios financieros } \\
\text { - Derivados }\end{array}$ \\
\hline Capitalista alternativa & Remuneración alternativa & Privada alternativa & Mercado alternativo & Mercado alternativo \\
\hline $\begin{array}{l}\text { - Propiedad estatal } \\
\text { - Ambientalmente } \\
\text { responsable } \\
\text { - Socialmente } \\
\text { responsable } \\
\text { - Sin ánimo de lucro }\end{array}$ & $\begin{array}{l}\text { - Autoempleo } \\
\text { - Cooperativista } \\
\text { - Aprendiz } \\
\text { - Trabajo colectivo } \\
\text { - Retribución en especie } \\
\text { - Trabajo a cambio de } \\
\text { prestación social }\end{array}$ & $\begin{array}{l}\text { - Propiedad estatal } \\
\text { - Propiedad grupal } \\
\text { tradicional } \\
\text { - Propiedad comunal } \\
\text { - Conocimiento popular }\end{array}$ & $\begin{array}{l}\text { - Comercio justo y directo } \\
\text { - Monedas alternativas } \\
\text { - Mercado negro } \\
\text { - Trueque } \\
\text { - Cooperativas de } \\
\text { consumo } \\
\text { - Agricultura sustentada } \\
\text { por la comunidad }\end{array}$ & $\begin{array}{l}\text { - Banca pública } \\
\text { - Banca cooperativa } \\
\text { - Cooperativas de crédito } \\
\text { - Préstamos públicos } \\
\text { - Instituciones financieras } \\
\text { comunitarias } \\
\text { - Microfinanzas } \\
\text { - Prestamistas }\end{array}$ \\
\hline No capitalista & Sin remuneración & Acceso abierto & No mercantil & No mercantil \\
\hline $\begin{array}{l}\text { - Cooperativas obreras } \\
\text { - Autónomos } \\
\text { - Empresa comunitaria } \\
\text { - Empresa feudal } \\
\text { - Empresa esclavista }\end{array}$ & $\begin{array}{l}\text { - Trabajo doméstico } \\
\text { - Cuidados familiares } \\
\text { - Voluntariado } \\
\text { - Trabajo en el vecindario } \\
\text { - Autoabastecimiento } \\
\text { - Esclavitud }\end{array}$ & $\begin{array}{l}\text { - Atmósfera } \\
\text { - Agua } \\
\text { - Océano (aguas } \\
\text { internacionales) } \\
\text { - Servicios ecosistémicos } \\
\text { - Espacio exterior }\end{array}$ & $\begin{array}{l}\text { - Hogar } \\
\text { - Regalos } \\
\text { - Pensión pública } \\
\text { - Caza, pesca } \\
\text { - Recolección } \\
\text { - Venta a pérdidas } \\
\text { - Robo, piratería, } \\
\text { furtivismo }\end{array}$ & $\begin{array}{l}\text { - Reparto de capital social } \\
\text { a trabajadores } \\
\text { - Fondos colectivos } \\
\text { de crédito } \\
\text { - Préstamos familiares } \\
\text { - Donativos } \\
\text { - Préstamo sin intereses } \\
\text { - Empresas financiadas } \\
\text { por la comunidad }\end{array}$ \\
\hline
\end{tabular}

Fuente: traducido de Gibson-Graham (2014: S150).

Ambas contribuciones ponen de relieve que la articulación de propiedad privada, mercado, competencia y salario que propone el capitalismo no es la única modalidad factible de coordinación económica, sino que existen otras fórmulas adicionales a aquellas que se expresan en el mercado a través de un precio de compraventa reflejado en la Contabilidad Nacional. Según Suriñach (2017: 28), estas taxonomías ensanchan la noción de lo económico más allá de la lógica del sector público (centrada en la redistribución), de la lógica lucrativa (plasmada en la competencia) y de la lógica financiera (propensa a la especulación). Estas tres lógicas visibles integrarían la economía "productiva», sustentada sobre otra economía «reproductiva», habitualmente invisible, compuesta por la economía cooperativa, la colaboración social, los cuidados domésticos y, como fundamento último, los procesos metabólicos que aseguran la reproducción de los ecosistemas naturales.

El segundo cuerpo de referencias teóricas que sustenta esta investigación se centra directamente en las economías alternativas, y se afana por desvelar su pluralidad efectiva y su dispar relación con el marco estructural (sobre todo económico, pero también social, cultural y político) que representa el capitalismo. 
Tabla 2. La diversidad de tipos de trabajo según White y Williams

\begin{tabular}{|c|c|c|c|c|c|c|}
\hline \multicolumn{6}{|c|}{ No monetizado } & \\
\hline \multirow{4}{*}{ 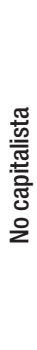 } & 1 & 3 & 5 & 7 & 9 & \\
\hline & $\begin{array}{l}\text { Trabajo no } \\
\text { intercambiado }\end{array}$ & $\begin{array}{l}\text { Intercambios } \\
\text { privados no } \\
\text { monetizados }\end{array}$ & $\begin{array}{l}\text { Trabajo organizado } \\
\text { no monetizado ni } \\
\text { declarado }\end{array}$ & $\begin{array}{l}\text { Trabajo formal } \\
\text { no pagado en el } \\
\text { sector público o } \\
\text { en el tercer sector }\end{array}$ & $\begin{array}{l}\text { Trabajo formal no } \\
\text { pagado en el sector } \\
\text { privado }\end{array}$ & \\
\hline & 2 & 4 & 6 & 8 & 10 & \\
\hline & $\begin{array}{l}\text { Trabajo familiar } \\
\text { monetizado }\end{array}$ & $\begin{array}{l}\text { Intercambios } \\
\text { comunitarios } \\
\text { monetizados }\end{array}$ & Trabajo informal & $\begin{array}{l}\text { Trabajo formal } \\
\text { pagado en el sector } \\
\text { público o en el } \\
\text { tercer sector }\end{array}$ & $\begin{array}{l}\text { Trabajo formal } \\
\text { pagado en el sector } \\
\text { privado }\end{array}$ & \\
\hline & & & Monetizado & & & \\
\hline
\end{tabular}

Fuente: traducido de White (2018: 340).

Ya en 2003, Fuller y Jonas clasificaron las alternativas según su «actitud» respecto al capitalismo. Las alternativas de «oposición» lo desafían de manera consciente para lograr su erradicación a través de soluciones económicas ajenas a toda autoridad y forma de explotación, sea entre humanos o entre estos y la naturaleza. Las alternativas de «sustitución» serían iniciativas locales que cubren necesidades colectivas desatendidas tras el repliegue neoliberal del Estado, pero no implican necesariamente un cuestionamiento explícito del orden establecido. Las alternativas de «adición» se apartan voluntariamente del capitalismo y del mercado para abrir espacios económicos gobernados por la reciprocidad entre los participantes (ver tabla 1, fila inferior, o tabla 2, celdas 1, 3 y 5).

Lee (2010) añade más "grados de alternatividad» a partir de la actitud que considera más radical, la de oposición (tabla 3). Un paso adicional en el cuestionamiento del capitalismo vendría dado por las alternativas de «desplazamiento», llamadas a reemplazar los circuitos de acumulación capitalista por otros mecanismos de generación y distribución del valor económico. En último término, propone la construcción de circuitos de valor regidos por motivos "éticos», como las tareas de cuidados interpersonales o la conservación de la naturaleza.

Tabla 3. Grados y formas de las economías alternativas al capitalismo

\begin{tabular}{llll}
\hline & & \multicolumn{2}{c}{ Formas de alternatividad } \\
\cline { 2 - 3 } Grados de alternatividad & Adición & Organizativa & Ambiental \\
\hline$(-) \quad$ Sustitución & & \\
& Oposición & & \\
& Desplazamiento & & \\
& Ética & & \\
& & & \\
\hline
\end{tabular}

Fuente: elaboración propia a partir de Lee (2010: 280). 
Además, Lee cruza esta «escala» de alternatividad con tres «formas de alternatividad»: "operacional», "ambiental» y "social». La primera remodela las prácticas capitalistas para terminar, a menudo, absorbida por el sistema, caso de la llamada "economía colaborativa» y sus gigantescas plataformas de servicios. La segunda redefine las relaciones entre naturaleza, economía y sociedad, como propugna la noción de "transición ecológica». Por alternativas sociales, a las que atribuye el máximo potencial transformador, Lee entiende las fórmulas de generación de valor que anteponen los beneficios colectivos a los individuales, caso de las alternativas éticas y de desplazamiento.

Esta preocupación académica por tipificar las PEA según su actitud ante el capitalismo es compartida por la literatura militante, escrita por personas vinculadas a los movimientos sociales que impulsan tales prácticas. Calle, Suriñach y Piñeiro (2017: 36ss) combinan dos variables para clasificar las economías alternativas (figura 1): "poder» y "compromiso". El ejercicio del poder puede variar desde un modelo vertical, jerárquico o centralizado (la propiedad de los recursos y la toma de decisiones están concentradas en pocas manos) hasta otro horizontal, distribuido o democrático (la propiedad de los recursos y la toma de decisiones corresponden a un amplio número de individuos). La segunda variable evalúa las alternativas según su implicación con la sostenibilidad ecológica, el desarrollo de vínculos comunitarios y territoriales, y la atención a los cuidados personales. Correspondería el mayor poder transformador a las alternativas que emplean modelos distribuidos orientados a la reproducción integral de la vida, mientras que las que recurren a modelos jerárquicos y operan básicamente en el mercado convencional serían las más próximas al capitalismo.

Sobre este diagrama, Suriñach (2017) sobreimpone tres áreas en función de su distancia ética (compromiso ecosocial) y organizativa (poder y recursos) al capitalismo. Las propuestas ${ }^{1}$ más cercanas al sistema se ubicarían en la zona de transacción: tienen una mayor difusión social, pero corren el riesgo de ser asimiladas por la economía capitalista o la Administración pública. Alrededor del punto donde se cruzan ambos ejes, se perfila una zona de hibridación poblada por organizaciones alternativas que han logrado consolidarse y cubrir necesidades concretas para un público en crecimiento. Las alternativas más transformadoras ocupan la zona de profundización: practican la democracia directa, dependen del trabajo voluntario, manejan recursos materiales muy escasos y son sensibles a los cuidados, la igualdad de género y el compromiso ambiental; aquí se ubicarían las PEA analizadas en este trabajo. Según Suriñach (2017: 146), las propuestas generadas en esta última zona pueden desplazarse hacia la de hibridación si ganan tamaño,

1. Distingue los movimientos (decrecimiento, economía del bien común, economía basada en los comunes, economías feministas y de los cuidados, economía social, economía social y solidaria) y los fenómenos (economías comunitarias, consumo responsable, economía circular, emprendimiento social, innovación social, responsabilidad social corporativa), más la economía colaborativa, a caballo entre ambas categorías. Esta relación incluye todas las posibilidades contempladas por Chaves y Monzón (2018, ver Introducción). 
Figura 1. Criterios para la clasificación de las economías transformadoras

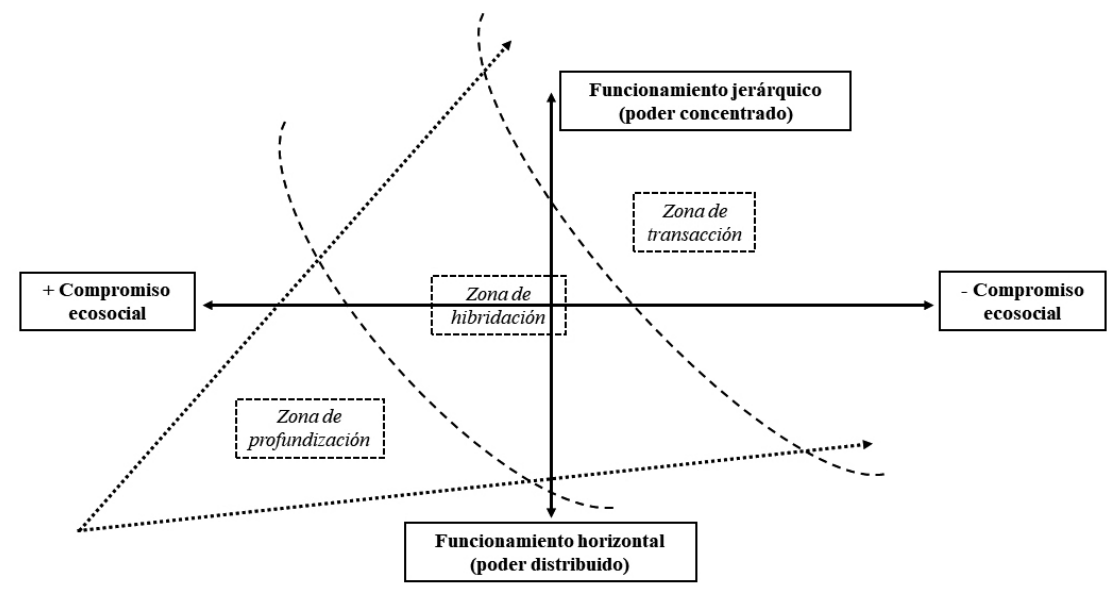

Fuente: elaboración propia a partir de Suriñach (2017: 128 y 145).

profesionalidad y capacidad de influencia política, hasta alcanzar la zona de transacción cuando se enfrentan a las contradicciones inherentes a la participación institucional y la adopción de conductas empresariales. Estas zonas pueden entenderse entonces, desde una perspectiva evolutiva, como fases sucesivas en la formulación, consolidación y difusión social, económica y geográfica de las PEA.

Estas tres zonas se corresponden, además, con la diferenciación que hacen Conill et al. (2012: 129) sobre el «perfil» de los involucrados en las PEA. En la zona de profundización se encontrarían los practicantes «alternativos» o "culturalmente transformadores", que buscan en las PEA una vía consciente para construir una sociedad no capitalista. En la zona de hibridación, los practicantes «no capitalistas» participan en estas prácticas sin atribuirles un pleno sentido transformador. En la zona de transacción, los practicantes «culturalmente adaptados» participan del modelo hegemónico y solo se involucran en las alternativas para satisfacer inquietudes individuales (acceso a alimentos saludables, recuperación del espacio público...).

La perspectiva gradualista que adopta este trabajo cuestiona la dicotomía esencialista entre capitalismo y alternativa (ambos en singular), y entiende la economía real como un continuo de combinaciones de los recursos económicos. Dicha perspectiva se apoya en los dos conjuntos de referencias conceptuales considerados en este apartado para desarrollar, en el siguiente, una metodología que reconoce la diversidad general de la economía para poner de relieve la diversidad particular de las economías que cuestionan el capitalismo y promueven alternativas que utilizan y combinan dichos recursos de manera específica y diferenciada. 


\section{Metodología de investigación}

Este artículo presenta los resultados de una investigación coordinada ${ }^{2}$ en las ciudades de Sevilla, Zaragoza, Alicante, Valladolid, Oviedo, Salamanca, León y Alcalá de Guadaíra. Esta muestra representa los diferentes niveles de la jerarquía urbana española, excepción hecha de Madrid y Barcelona, cuyas economías alternativas han sido parcialmente estudiadas en otros trabajos (Subirats y García, 2015; Fernández y Miró, 2016; Suriñach, 2017; Méndez y Monteserín, 2019).

La definición propuesta en la introducción no especifica la organización espacial de las PEA. Puede tratarse de actividades de escala local, con una sede física (hogar, solar, plaza, local, espacio okupado) de trabajo para los participantes, pero también de redes nacionales o internacionales cuya operatividad no exige esa copresencia, caso del comercio justo, las comunidades digitales o las finanzas éticas. Esta investigación se ha centrado en PEA locales, que se nutren de recursos humanos y materiales arraigados en el entorno geográfico inmediato.

Se aplicó el siguiente procedimiento para identificar y analizar las PEA de cada ciudad (Moro y Lamarque, 2019). Mediante trabajo de campo y rastreos en internet, se confeccionó un inventario de las PEA activas, tomando como referencia general una relación de unas sesenta modalidades confeccionada tras la revisión de la literatura especializada. Después, se seleccionaron las modalidades más frecuentes, presentes en mayor número de ciudades y ubicadas en todas las etapas del circuito económico: cuidados (bancos del tiempo), producción (huertos urbanos), distribución (mercados de productores y de trueque), consumo (grupos de consumo ecológico), financiación (monedas sociales y locales), más los centros sociales autogestionados, lugar de encuentro habitual entre las personas implicadas en estas iniciativas y que la literatura identifica como laboratorios de ideas y actividades de acentuado talante crítico, además de cumplir una destacada función como espacios de ocio desmercantilizado y alternativo a la oferta capitalista convencional (Bresnihan y Byrne, 2015; Yates, 2015).

Para el estudio de cada tipo de PEA, se confeccionó un dossier metodológico compuesto por cinco herramientas:

2. Esta publicación se encuadra en el proyecto de investigación "Espacios y prácticas económicas alternativas para la construcción de la resiliencia en las ciudades españolas» (enero de 2016 - junio de 2019). Programa Estatal de I+D+I-Reto, financiado por el MINECO-FEDER (referencia CSO2015-65452-R). Entidades participantes: Instituto de Ciencias Sociales (Universidad de Lisboa), Instituto de Economía, Geografía y Demografía (CSIC, Madrid) y universidades de Alicante, Heidelberg, León, Pablo de Olavide (Sevilla), Salamanca (coordinadora), Sevilla, Valladolid y Zaragoza. Este proyecto participó en la Red Temática de Excelencia "Retos para las ciudades del siglo xxI: una agenda de investigación para la construcción de espacios urbanos sostenibles e innovadores", financiada por el Plan Estatal de Fomento de la Investigación Científica y Técnica de Excelencia 2013-2016 (referencia CSO2016-81718-REDT), coordinada por la Universitat Autònoma de Barcelona (julio de 2017 - junio de 2019). 
- Definición de la PEA y criterios para la inclusión de cada caso concreto en la investigación.

- Ficha de toma de datos: nombre, dirección postal y electrónica, naturaleza jurídica (en su caso), fecha de fundación, número de participantes, escala de trabajo, tipo de sede, horario de apertura, mecanismo de toma de decisiones, actividades habituales y cooperación con otras PEA.

- Guion de entrevista semiestructurada (con los representantes de cada PEA) y cuestionario estandarizado (distribuido a los participantes): estos dos instrumentos constan de una serie de preguntas comunes a las seis clases de PEA y otras específicas para cada una de ellas.

- Tabla de criterios, cumplimentada con la información de la entrevista y el análisis de los sitios de internet de cada caso. Esta tabla es común para todas las PEA y consta de ocho variables: organización, propiedad, financiación, retribución del trabajo, modalidad de participación en la producción del bien/servicio, modalidad de acceso al bien/servicio, medio de pago del bien/ servicio y escala geográfica de acción. Cada variable se desglosa en una serie cerrada de opciones, de respuesta única o múltiple, para facilitar la cuantificación de los datos.

Entre mayo de 2017 y abril de 2018, este dossier fue aplicado en cada ciudad a las PEA que accedieron a colaborar en la investigación, cuya distribución recoge la tabla 4. Predominan, con un 66\%, las PEA relacionadas con la alimentación (grupos, huertos y mercados), dato consistente con otras investigaciones (Conill et al., 2012; Méndez y Monteserín, 2019) y que muestra la difusión de las redes ciudadanas que reconectan a consumidores urbanos con productores agropecuarios de proximidad y desafían el poder del sistema alimentario globalizado.

El total estimado de participantes en estas 67 PEA es de 5.261 personas. Se trata, pues, de propuestas de muy pequeño tamaño, con un promedio de 78 personas involucradas, aunque algunas frisan en la decena y otras rebasan el medio millar (bancos del tiempo en Zaragoza y Valladolid, moneda social de Sevilla). Se obtuvieron 468 respuestas válidas a los cuestionarios. La muestra está integrada en un 55\% por mujeres, su edad media se sitúa en 47,5 años y el $92,5 \%$ posee nacionalidad española. Su nivel educativo es elevado $(62 \%$ con estudios universitarios), congruente con una alta inserción laboral (68\% de empleados por cuenta propia o ajena) y la pertenencia a hogares con un nivel de renta medio o medio-alto, pues el $43,7 \%$ declara ingresar entre 20.000 y 40.000 euros anuales - cuando el promedio español en 2016 era de 26.730 euros, según el INE—, más otro 10\% que rebasa los 40.000 euros.

Este trabajo explota los datos consignados en la tabla de criterios (tabla 5), que sintetiza las dos líneas de análisis expuestas en el apartado anterior. A la composición original de la tabla se ha añadido aquí el criterio Sede, extraído de la ficha de datos. Conforme a la tesis gradualista ya expuesta, la tabla de criterios asume que las PEA intentan resolver necesidades económicas de muy distinta índole, igual que las empresas capitalistas convencionales. En cuanto a 
Tabla 4. Distribución de las PEA estudiadas por tipos y ciudades

\begin{tabular}{lccccccc}
\hline \multicolumn{1}{c}{ Ciudad } & $\begin{array}{c}\text { Bancos } \\
\text { del tiempo }\end{array}$ & $\begin{array}{c}\text { Centros sociales } \\
\text { autogestionados }\end{array}$ & $\begin{array}{c}\text { Grupos } \\
\text { consumo } \\
\text { ecológico }\end{array}$ & $\begin{array}{c}\text { Huertos } \\
\text { urbanos }\end{array}$ & $\begin{array}{c}\text { Mercados de } \\
\text { productores/ } \\
\text { trueque }\end{array}$ & $\begin{array}{c}\text { Moneda } \\
\text { social/local }\end{array}$ & Total \\
\hline Alcalá de Guadaíra & - & - & - & - & - & 1 & 1 \\
Alicante & 1 & 1 & 3 & - & 1 & - & 6 \\
León & - & 1 & 3 & 1 & 1 & - & 6 \\
Oviedo & 1 & 1 & - & 1 & 1 & 1 & 5 \\
Salamanca & 1 & 2 & 3 & 3 & 1 & 1 & 11 \\
Sevilla & - & - & - & - & - & 1 & 1 \\
Valladolid & 1 & 5 & 9 & 8 & 1 & 1 & 25 \\
Zaragoza & 1 & 2 & 2 & 4 & 2 & 1 & 12 \\
Total & 5 & 12 & 20 & 17 & 7 & 6 & 67 \\
\hline
\end{tabular}

Fuente: elaboración propia.

soluciones económicas, unas y otras deben disponer de unos recursos básicos y organizar tanto su actividad interna como sus relaciones con actores externos. Las diferencias entre ellas, entonces, deberían estribar en la forma concreta de reunir los recursos y de articular tales relaciones. En otras palabras, estas prácticas tendrían que mostrar un perfil dotacional, organizativo y relacional específico para ser auténticamente alternativas al capitalismo.

La primera columna (Criterio) recupera las taxonomías de Gibson-Graham y de White y Williams (tablas 1 y 2) y desglosa esos nueve recursos (criterios $2,3,4$ y 9) y decisiones organizativas (criterios $1,5,6,7$ y 8) comunes a toda solución económica. Las columnas siguientes siguen a Lee (tabla 3) y Suriñach (figura 1), y establecen una gradación — forzosamente simplificadora de una intrincada realidad empírica - entre lo convencional y lo alternativo. La segunda columna representa la solución-tipo característica de la empresa capitalista con ánimo de lucro, propiedad privada de los recursos, financiación en el sistema bancario o bursátil, que abona salarios en moneda de curso legal, adquiere sus insumos en un mercado competitivo, ofrece sus bienes a todo consumidor capaz de pagarlos, cobra y paga en moneda de curso legal, no se plantea restricciones geográficas en su funcionamiento y dispone de una sede en propiedad o alquiler. A partir de ahí, cada fila, independiente de las demás, desglosa otras opciones cada vez más alternativas o distantes de la norma de referencia sintetizando los contenidos de las tablas 1 y 2 .

La aplicación de esta metodología a los datos empíricos destacará cuatro aspectos. Primero, la variedad de formas de coordinación económica de carácter no capitalista. Segundo, la diversidad interna de las fórmulas alternativas, que no responden a un único formato, aunque presentan rasgos comunes que expresan su voluntad y capacidad para desarrollar una economía diferente. Tercero, la identificación de los puntos de convergencia y divergencia entre PEA y empresa convencional. Estos tres aspectos son imprescindibles para identificar, por último, los anclajes de la propuesta transformadora de las PEA. 
Tabla 5. Criterios para el análisis de la organización de las prácticas económicas alternativas

\begin{tabular}{|c|c|c|c|c|c|c|c|c|}
\hline \multirow{2}{*}{$\frac{\text { Criterio }}{1 \text { Organización }}$} & \multicolumn{8}{|c|}{ Opciones a lo largo de un eje convencional $\rightarrow$ alternativo } \\
\hline & $\begin{array}{l}\text { Empresa } \\
\text { con ánimo } \\
\text { de lucro }\end{array}$ & $\begin{array}{l}\text { Empresa } \\
\text { de economía } \\
\text { social }\end{array}$ & $\begin{array}{l}\text { Administración } \\
\text { pública }\end{array}$ & $\begin{array}{l}\text { Organización } \\
\text { del tercer } \\
\text { sector }\end{array}$ & $\begin{array}{l}\text { Asociación } \\
\text { legalizada }\end{array}$ & $\begin{array}{l}\text { Colectivo sin } \\
\text { reconocimiento } \\
\text { legal, pero } \\
\text { tolerado por la } \\
\text { Administración }\end{array}$ & $\begin{array}{l}\text { Economía } \\
\text { informal }\end{array}$ & \\
\hline 2 Propiedad & Privada & Colectiva & Comunal & $\begin{array}{l}\text { Sin recursos } \\
\text { físicos en } \\
\text { propiedad }\end{array}$ & & & & \\
\hline 3 Financiación & $\begin{array}{l}\text { Sistema financiero } \\
\text { (banca, bolsa) }\end{array}$ & $\begin{array}{l}\text { Cooperativas } \\
\text { de crédito }\end{array}$ & $\begin{array}{l}\text { Banca ética } \\
\text { autorizada }\end{array}$ & $\begin{array}{l}\text { Subvenciones } \\
\text { públicas }\end{array}$ & $\begin{array}{l}\text { Cuotas } \\
\text { obligatorias }\end{array}$ & $\begin{array}{l}\text { Aportaciones } \\
\text { voluntarias }\end{array}$ & $\begin{array}{l}\text { Recursos } \\
\text { propios }\end{array}$ & $\begin{array}{l}\text { Sin uso } \\
\text { de dinero }\end{array}$ \\
\hline $\begin{array}{l}4 \text { Retribución } \\
\text { del trabajo }\end{array}$ & Salario en euros & $\begin{array}{l}\text { Asignación } \\
\text { en euros } \\
\text { (anual, no } \\
\text { periódica...) }\end{array}$ & $\begin{array}{l}\text { Retribución } \\
\text { (total o parcial) } \\
\text { en moneda } \\
\text { social }\end{array}$ & $\begin{array}{l}\text { Retribución } \\
\text { en especie } \\
\text { (incluido el } \\
\text { trabajo) }\end{array}$ & $\begin{array}{l}\text { Voluntario } \\
\text { (gratuito) }\end{array}$ & & & \\
\hline $\begin{array}{l}5 \text { Modalidad de } \\
\text { participación } \\
\text { en la producción } \\
\text { del bien/servicio }\end{array}$ & $\begin{array}{l}\text { Participación } \\
\text { abierta }\end{array}$ & $\begin{array}{l}\text { Participación } \\
\text { sujeta a } \\
\text { admisión por } \\
\text { los miembros } \\
\text { de la iniciativa }\end{array}$ & $\begin{array}{l}\text { Participación } \\
\text { limitada por el } \\
\text { tamaño de la } \\
\text { iniciativa }\end{array}$ & & & & & \\
\hline $\begin{array}{l}6 \text { Modalidad } \\
\text { de acceso al } \\
\text { bien/servicio }\end{array}$ & $\begin{array}{l}\text { Acceso libre en } \\
\text { local o espacio } \\
\text { legalizado }\end{array}$ & $\begin{array}{l}\text { Acceso libre, } \\
\text { pero limitado } \\
\text { a espacios } \\
\text { adheridos a } \\
\text { una red }\end{array}$ & $\begin{array}{l}\text { Acceso } \\
\text { restringido a } \\
\text { miembros de } \\
\text { la iniciativa }\end{array}$ & & & & & \\
\hline $\begin{array}{l}7 \text { Medio de pago } \\
\text { del bien/servicio }\end{array}$ & $\begin{array}{l}\text { Moneda de curso } \\
\text { legal }\end{array}$ & Moneda social & Trueque & Tiempo & Gratuidad & & & \\
\hline $\begin{array}{l}8 \text { Escala } \\
\text { geográfica }\end{array}$ & Indiferente & Regional & Ciudad & Barrio & & & & \\
\hline 9 Sede & Propiedad/alquiler & $\begin{array}{l}\text { Cedida por la } \\
\text { Administración }\end{array}$ & $\begin{array}{l}\text { Cedida por } \\
\text { asociación }\end{array}$ & $\begin{array}{l}\text { Cedida por } \\
\text { particular }\end{array}$ & $\begin{array}{l}\text { Espacio } \\
\text { público al } \\
\text { aire libre }\end{array}$ & Local okupado & Sin sede & \\
\hline
\end{tabular}

Nota: los criterios $3,4,7$ y 8 son de respuesta múltiple.

Fuente: elaboración propia.

\section{Resultados: unidad y diversidad organizativa de las prácticas económicas alternativas}

Dada la desigual distribución de la muestra por ciudades y tipos de PEA (tabla 4), este apartado expone los datos agregados de los 67 casos estudiados, una escala que no se ha tratado en detalle hasta ahora (ver tabla 6). Otros estudios apoyados en esta misma metodología se han centrado en las ciudades de Valladolid (Pascual et al., 2018) y León (Benito y López, 2019), o en las monedas sociales (Caravaca y González, 2019), los bancos del tiempo (Climent y Lardiés, 2019), los grupos de consumo (Espinosa, 2019) y los mercados de productores (Espinosa et al., 2020). 
Tabla 6. Distribución de los recursos y formas de organización de las prácticas económicas alternativas urbanas analizadas

\begin{tabular}{|c|c|c|c|c|c|c|c|c|c|}
\hline \multicolumn{2}{|c|}{ Criterio } & \multicolumn{8}{|c|}{ Opciones a lo largo de un eje convencional $\rightarrow$ alternativo } \\
\hline \multirow[t]{2}{*}{1} & $\begin{array}{l}\text { Organización } \\
(67)\end{array}$ & $\begin{array}{l}\text { Empresa } \\
\text { con ánimo } \\
\text { de lucro }\end{array}$ & $\begin{array}{l}\text { Empresa de } \\
\text { economía social }\end{array}$ & $\begin{array}{l}\text { Administración } \\
\text { pública }\end{array}$ & $\begin{array}{l}\text { Organización } \\
\text { del tercer } \\
\text { sector }\end{array}$ & $\begin{array}{l}\text { Asociación } \\
\text { legalizada }\end{array}$ & $\begin{array}{l}\text { Colectivo sin } \\
\text { reconocimiento } \\
\text { legal, pero } \\
\text { tolerado por la } \\
\text { Administración }\end{array}$ & $\begin{array}{l}\text { Economía } \\
\text { informal }\end{array}$ & \\
\hline & & 1 & 7 & 3 & 11 & 15 & 28 & 2 & \\
\hline \multirow[t]{2}{*}{2} & $\begin{array}{l}\text { Propiedad } \\
\text { (67) }\end{array}$ & Privada & $\begin{array}{l}\text { Administración } \\
\text { pública }\end{array}$ & Colectiva & Comunal & $\begin{array}{l}\text { Sin recursos } \\
\text { físicos en } \\
\text { propiedad }\end{array}$ & & & \\
\hline & & 4 & 2 & 3 & 6 & 52 & & & \\
\hline \multirow[t]{2}{*}{3} & $\begin{array}{l}\text { Financiación } \\
\text { (83) }\end{array}$ & $\begin{array}{l}\text { Sistema } \\
\text { financiero } \\
\text { (banca, bolsa) }\end{array}$ & $\begin{array}{l}\text { Cooperativas } \\
\text { de crédito }\end{array}$ & $\begin{array}{l}\text { Banca ética } \\
\text { autorizada }\end{array}$ & $\begin{array}{l}\text { Subvenciones } \\
\text { públicas }\end{array}$ & $\begin{array}{l}\text { sCuotas } \\
\text { obligatorias }\end{array}$ & $\begin{array}{l}\text { Aportaciones } \\
\text { voluntarias }\end{array}$ & $\begin{array}{l}\text { Recursos } \\
\text { propios }\end{array}$ & $\begin{array}{l}\text { Sin uso } \\
\text { de dinero }\end{array}$ \\
\hline & & 0 & 1 & 1 & 12 & 17 & 23 & 24 & 5 \\
\hline \multirow[t]{2}{*}{4} & $\begin{array}{l}\text { Retribución del } \\
\text { trabajo } \\
\text { (73) }\end{array}$ & $\begin{array}{l}\text { Salario } \\
\text { en euros }\end{array}$ & $\begin{array}{l}\text { Asignación en } \\
\text { euros (anual, } \\
\text { no periódica...) }\end{array}$ & $\begin{array}{l}\text { Retribución } \\
\text { (total o parcial) } \\
\text { en moneda social }\end{array}$ & $\begin{array}{l}\text { Retribución } \\
\text { en especie } \\
\text { (incluido el } \\
\text { trabajo) }\end{array}$ & $\begin{array}{l}\text { Voluntario } \\
\text { (gratuito) }\end{array}$ & No consta & & \\
\hline & & 16 & 5 & 1 & 1 & 49 & 1 & & \\
\hline \multirow[t]{2}{*}{5} & $\begin{array}{l}\text { Modalidad de } \\
\text { participación en } \\
\text { la producción } \\
\text { del bien/servicio }\end{array}$ & $\begin{array}{l}\text { Participación } \\
\text { abierta }\end{array}$ & $\begin{array}{l}\text { Participación } \\
\text { sujeta a admisión } \\
\text { por los miembros } \\
\text { de la iniciativa }\end{array}$ & $\begin{array}{l}\text { Participación } \\
\text { limitada por el } \\
\text { tamaño de la } \\
\text { iniciativa }\end{array}$ & & & & & \\
\hline & & 25 & 29 & 13 & & & & & \\
\hline \multirow[t]{2}{*}{6} & $\begin{array}{l}\text { Modalidad de } \\
\text { acceso al bien/ } \\
\text { servicio } \\
\text { (67) }\end{array}$ & $\begin{array}{l}\text { Acceso libre en } \\
\text { local o espacio } \\
\text { legalizado }\end{array}$ & $\begin{array}{l}\text { Acceso libre, } \\
\text { pero limitado } \\
\text { a espacios } \\
\text { adheridos a } \\
\text { una red }\end{array}$ & $\begin{array}{l}\text { Acceso restringido } \\
\text { a miembros de la } \\
\text { iniciativa }\end{array}$ & & & & & \\
\hline & & 35 & 2 & 30 & & & & & \\
\hline \multirow[t]{2}{*}{7} & $\begin{array}{l}\text { Medio de pago } \\
\text { del bien/servicio } \\
\text { (76) }\end{array}$ & $\begin{array}{l}\text { Moneda de } \\
\text { curso legal }\end{array}$ & Moneda social & Trueque & Tiempo & Gratuidad & & & \\
\hline & & 35 & 8 & 6 & 7 & 20 & & & \\
\hline \multirow[t]{2}{*}{8} & $\begin{array}{l}\text { Escala geo- } \\
\text { gráfica }\end{array}$ & Indiferente & Regional & Provincial & Ciudad & Barrio & & & \\
\hline & (95) & 0 & 14 & 4 & 44 & 33 & & & \\
\hline \multirow[t]{2}{*}{9} & $\begin{array}{l}\text { Sede } \\
(67)\end{array}$ & $\begin{array}{l}\text { Propiedad/ } \\
\text { alquiler }\end{array}$ & $\begin{array}{l}\text { Cedida por Admi- } \\
\text { nistración }\end{array}$ & $\begin{array}{l}\text { Cedida por aso- } \\
\text { ciación }\end{array}$ & $\begin{array}{l}\text { Cedida por } \\
\text { particular }\end{array}$ & $\begin{array}{l}\text { Espacio } \\
\text { público al } \\
\text { aire libre }\end{array}$ & Local okupado & Sin sede & \\
\hline & & $2 / 18$ & 19 & 6 & 6 & 5 & 9 & 2 & \\
\hline
\end{tabular}

Nota: los criterios 3, 4, 7 y 8 son de respuesta múltiple. En cada criterio figura, entre paréntesis, el número total de respuestas marcadas.

Fuente: elaboración propia. 
En una primera lectura, la tabla 6 confirma las posiciones de la literatura teórica presentada anteriormente. Para una relación básica de nueve recursos y formas de organización, los datos demuestran que el modelo capitalista convive en la vida real con toda una pluralidad de posibilidades que son movilizadas o combinadas de formas diversas para construir una alternatividad que tampoco es monolítica, puesto que en casi todos los criterios aparecen valores positivos en todas las opciones de la tabla. Los únicos ceros corresponden, justamente, a opciones ubicadas en la segunda columna, que sintetiza el funcionamiento básico de la empresa con ánimo de lucro. Sin embargo, esa diversidad de lo alternativo no oculta el predominio de una serie de rasgos que se presentan a continuación.

\subsection{Principales caracteristicas organizativas de las PEA}

El perfil dominante de las PEA viene definido por los valores más frecuentes en cada criterio de la tabla 6 . En el $42 \%$ de los casos, los promotores de las PEA son colectivos ciudadanos organizados de manera informal, sin personalidad jurídica alguna (criterio 1. Organización): recuérdese que su tamaño medio es inferior al centenar de individuos. Su funcionamiento interno es asambleario, según las entrevistas y fichas de datos. Todas las personas implicadas tienen derecho a participar en los encuentros periódicos (quincenales, mensuales), donde se toman, casi siempre por consenso, las decisiones sobre el funcionamiento de la iniciativa. Se evita cualquier proceso de especialización funcional o de división social del trabajo mediante la asignación rotatoria (pero obligatoria) de las funciones que requiere el mantenimiento de la actividad. Generalmente, estas funciones se desempeñan de manera gratuita y no retribuida, opción mencionada por el $73,1 \%$ de la muestra en el criterio 4. Retribución del trabajo (respuesta múltiple).

Como anticipa esta informalidad jurídica, el 77,6\% de las PEA carecen de activos físicos y operan sin máquinas, equipos, terrenos o instalaciones propias (criterio 2. Propiedad). Solo dos casos funcionan desde una sede propia (criterio 9. Sede): el uso de espacios cedidos por la Administración (28,3\%) o alquilados a particulares $(26,8 \%)$ son las fórmulas principales de acceso a un local donde desarrollar sus labores.

El criterio 3. Financiación es también de respuesta múltiple, dado que una misma PEA puede recurrir a más de una solución para reunir los fondos que precisa. Dos son las mayoritarias: una, el uso compartido de recursos personales de los participantes (ahorros, instrumental), al que recurre un 35,8\% de las PEA; dos, las contribuciones voluntarias no periódicas de los mismos $(34,3 \%)$, dirigidas a solventar necesidades puntuales o sufragar los períodos de especial actividad, como sucede en las prácticas más sujetas a la estacionalidad (grupos de consumo, huertos).

Estos cinco criterios $(1,2,3,4$ y 9$)$ se refieren a cuestiones internas a la PEA. Los otros cuatro $(5,6,7$ y 8$)$ definen sus relaciones con el entorno socioeconómico. El criterio 5. Modalidad de participación en la producción 
del bien/servicio se refiere a la forma en que una persona u organización puede involucrarse como proveedor, oferente o prosumidor. La opción principal $(43,2 \%)$ limita la participación a un proceso de admisión previa por parte de la asamblea, sean los agricultores que abastecen a un grupo de consumo, los individuos que intercambian servicios en un banco del tiempo o quienes desean usar una moneda local como medio de intercambio. Desde el otro punto de vista (criterio 6. Modalidad de acceso al bien/servicio generado en la PEA), predomina (52,2\%) el libre acceso del público, sobre todo en los de carácter más mercantil (mercados de productores) o participativo (centros sociales autogestionados), cuyo éxito depende de la afluencia de numerosas personas. El criterio 7. Medio de pago (respuesta múltiple) demuestra el predominio del sistema monetario hegemónico, pues el 52,3\% de las iniciativas admiten usar la moneda de curso legal en los intercambios. Los criterios de selección de la muestra, por último, condicionan los resultados del criterio 9. Escala geográfica de actuación (respuesta múltiple), dominado por las escalas de proximidad: el 65,6\% se refiere a la ciudad como ámbito operativo y el $49,2 \%$ cita el barrio como marco geográfico principal de referencia.

En resumen, las PEA no funcionan como personas jurídicas, sino como pequeños colectivos ciudadanos carentes de otros recursos materiales que no sean los personales de sus integrantes, quienes sostienen la actividad con su trabajo voluntario. Estas restricciones de capital (incluido el espacio físico), junto con la voluntad - manifiesta en las entrevistas - por conservar el espíritu comunitario y evitar la implantación de modelos organizativos de tipo jerárquico y especializado, explicarían la preferencia por limitar el número de personas involucradas. En la mayoría de las ocasiones, facilitan la distribución del producto/servicio a cualquier usuario interesado, sobre todo del entorno geográfico más próximo, con el euro como medio de pago más difundido.

Por tanto, una PEA tipo difiere de la empresa capitalista convencional en seis puntos fundamentales: la forma de organización, la propiedad de los recursos, la financiación de la actividad, la retribución del trabajo, la delimitación consciente de su ámbito geográfico de actuación y, en menor grado, la selección de sus integrantes y proveedores por criterios no competitivos. Sin embargo, hay tres facetas donde esa diferencia se torna confluencia: la voluntad de captar todo tipo de usuarios, el empleo de la moneda de curso legal para la compraventa de productos y servicios, y el recurso al alquiler para disponer de una sede operativa. Las diferencias, entonces, radican sobre todo en las cuestiones internas (criterios 1, 2, 3 y 4), mientras que las semejanzas se concentran en los criterios relacionados con los vínculos externos (criterios 6 y 7) y en la sede física (criterio 9). El criterio 5 puede ser materia de discusión, tanto por la distribución de los datos (la participación abierta está muy extendida) como por el hecho de que también la empresa convencional selecciona a sus proveedores y empleados para fortalecer su capacidad competitiva. Esta cuestión abre paso al examen de la patente diversidad de soluciones alternativas que refleja la tabla 6 . 


\subsection{Variedad organizativa de las PEA}

Un amplio número de PEA adopta, al menos de forma parcial, fórmulas operativas más convencionales. El 49\% se registran como personas jurídicas (sumando empresas de economía social, organización del tercer sector y simples asociaciones) y tres casos han sido promovidos por la Administración local (criterio 1. Organización). Ello les permite, según las entrevistas, acceder a algunas ayudas municipales, firmar contratos de alquiler y suministro, disponer de una cuenta bancaria, abrir una pequeña tienda de alimentación o artesanía e incluso abonar un modesto salario a las personas más dedicadas al proyecto, como sucede en el $24 \%$ de las PEA (criterio 4. Retribución). Estas estructuras son más costosas de mantener, así que un $25 \%$ de los casos fija cuotas obligatorias de pago periódico y un $18 \%$ reconoce recibir subvenciones públicas (criterio 3. Financiación). En cuanto al criterio 8. Escala geográfica, llama la atención el amplio radio de acción de cierto número de PEA, toda vez que algo más de la cuarta parte trabajan en el nivel regional o provincial, pese a sus precarios recursos.

Por tanto, incluso en los criterios de tipo interno, donde las PEA distan más de la empresa convencional (ver apartado 4.1), los datos dibujan una gestión de los recursos no exenta de rasgos capitalistas: formalización jurídica, delegación de funciones con retribución salarial, reconocimiento de la propiedad privada a través del pago de alquileres, interacción —e incluso colaboración- con la Administración local (cesión de espacios para bancos del tiempo, huertos urbanos o mercados), abono de cuotas a modo de participación societaria o apertura de puntos de venta al público para financiar al menos una parte de los gastos.

Ya se ha dicho que, en lo tocante a los criterios que expresan los vínculos con el entorno, las PEA se aproximan al modelo empresarial hegemónico. Por tanto, la diversidad opera ahora en el sentido opuesto. Los datos reflejan la existencia, minoritaria pero efectiva, de experiencias alternativas como la gratuidad (criterio 7. Medio de pago) o el empleo de monedas no convencionales (social, tiempo, trueque), cada una de las cuales es citada por el $30 \%$ de las PEA. Las soluciones abiertas o de mercado en los criterios 5. Modalidad de participación y 6. Modalidad de acceso dejan amplio espacio a otras donde solo los miembros reconocidos de la PEA pueden ser productores o consumidores, bien por motivos ideológicos (conservación de los vínculos comunitarios) o prácticos (escasez de recursos humanos, insuficiente tamaño de las sedes). Algo parecido sucede con el criterio 9. Sede, puesto que el 39\% de las PEA operan en espacios no convencionales (locales okupados, al aire libre) o en locales cedidos gratuitamente por colectivos y particulares.

En definitiva, el perfil mayoritario definido en el apartado 4.1 no debe eclipsar la pluralidad de soluciones adoptadas por estas PEA. Por una parte, se combinan recursos (criterios 2, 3, 4 y 9) y formas organizativas (criterio 1) de índole comunitaria con otras habituales en la empresa mercantil. Por otra, la inserción en el entorno local (criterios 5, 6 y 7), definido de manera muy fluida por los involucrados (criterio 8), se resuelve con un mayor equilibrio 
entre las opciones disponibles, señal de cierta convergencia entre empresas convencionales y PEA en su búsqueda de proyección social.

\section{3. ¿Dónde radica la alternatividad de las PEA?}

¿Qué aportan estos resultados al debate sobre la naturaleza operativa de las PEA y los argumentos de su propuesta transformadora? La figura 2 combina los datos de la tabla 6 con la propuesta analítica de la figura 1. El triángulo isósceles que representa cada criterio ${ }^{3}$ tiene su base en la zona donde sus valores son más elevados, asumiendo que la zona de transacción corresponde a la segunda columna (empresa con ánimo de lucro) y la zona de profundización a los valores alternativos más alejados de la misma.

La figura refleja que la alternatividad se construye sobre tres pilares: la organización (forma jurídica), los recursos internos (propiedad, financiación y trabajo) y la escala local de actuación, todos anclados en la zona de profundización. Las PEA proponen una forma de producir bienes y servicios de índole comunal, cooperativa e independiente del sistema financiero. La participación es la clave de estas iniciativas donde se difuminan las oposiciones binarias (productor-consumidor, gerencia-trabajo), a fin de reunificar las esferas de la vida y la economía (escindidas por la acción del capitalismo) bajo la primacía de la primera, como insisten las entrevistas. Todo ello en un marco de proximidad geográfica que provee los recursos materiales y los espacios de interacción social que garantizan la confianza interpersonal indispensable para el funcionamiento de las PEA.

Sin embargo, las PEA también dirigen su proyecto al conjunto de la sociedad, como las empresas convencionales. Muchas admiten la participación de cualquier persona, distribuyen sus bienes al público general y admiten euros en sus transacciones. Mientras la producción reviste formatos más alternativos, los criterios de distribución se asientan en la zona de transacción, donde conviven con la economía hegemónica. Así, las PEA rivalizan con las empresas mercantiles en el espacio público con un modo específico y localizado de organización productiva.

En este sentido, no es casual que las sedes sean el único recurso interno concentrado en esta zona de transacción. No solo congregan a los involucrados en las tareas productivas, constituyen, sobre todo, el principal punto físico de contacto entre las economías alternativas y el resto de la sociedad: huertos, mercados o locales están llamados a atraer la atención de quienes desconocen estas PEA y a difundir las capacidades transformadoras de su labor cotidiana.

No obstante, ese punto de contacto opera en un doble sentido. Comunica el espacio alternativo con el convencional, pero somete el primero a dos principios muy cuestionados por el pensamiento crítico: el respeto a la propiedad privada y el cumplimiento de las disposiciones dictadas por las administracio-

3. Los criterios 5 y 6 se representan con rectángulos porque sus valores no pueden asignarse de forma concluyente a una sola de las tres zonas. 
Figura 2. Los recursos y las formas de organización alternativas en las tres zonas de transformación

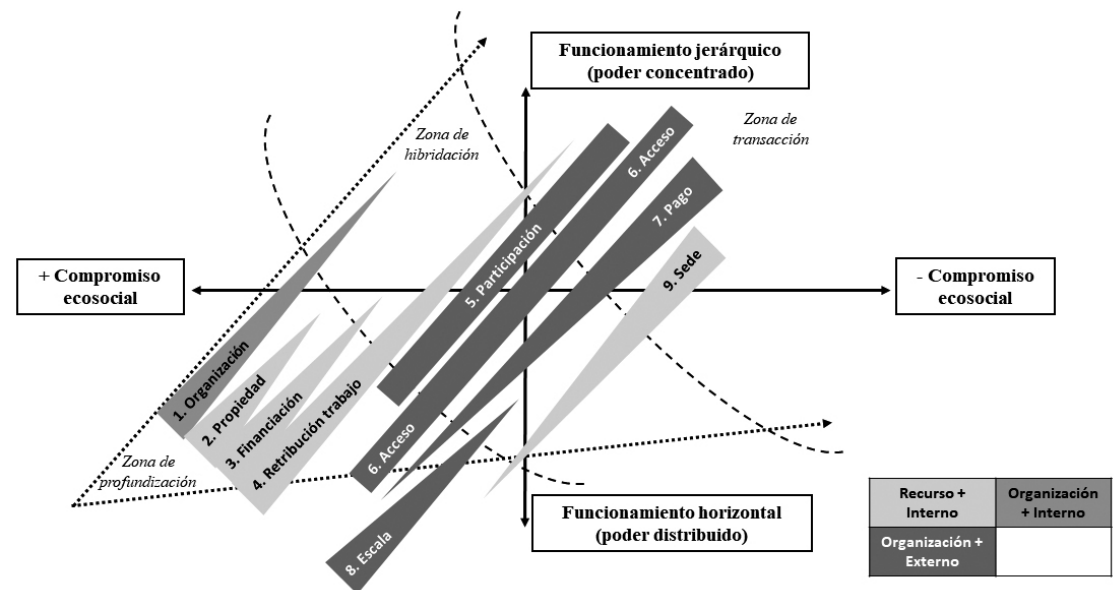

Fuente: elaboración propia.

nes. El 55\% de las sedes son propiedad de los ayuntamientos o arrendadas a personas físicas (tabla 6). Su uso requiere el acatamiento de normas (actividades, horarios, higiene, seguridad, aforo) y el pago de alquileres y gastos que detraen esfuerzos y fondos desde el circuito alternativo al convencional. La naturaleza de los recursos (humanos, materiales, organizativos) de estas PEA, sumada a la reticencia ideológica ante la autoridad y ante la generación de excedentes no destinados a cubrir necesidades fundamentales, sino al lucro de poderes entendidos como ajenos o alienantes, es su máxima seña de identidad, pero se torna debilidad cuando se trata de coexistir con empresas habituadas al contexto del mercado y la autoridad.

Las entrevistas, otra vez, están llenas de pasajes que narran las dificultades para abonar el alquiler o cumplir requisitos legales que han abocado al cierre a varias iniciativas. En ellas se exponen también las fórmulas ideadas para afrontar estas exigencias: colectas extraordinarias, organización de mercadillos y festejos populares, realquiler de espacios para cursos y talleres, abono de pequeños salarios para lograr una gestión eficaz y abaratar costes de funcionamiento...

Las obligaciones inherentes a la inserción de las PEA en una socioeconomía capitalista justifican la adopción estas soluciones híbridas, con elementos alternativos y convencionales (figura 2). Según la tabla 6, la alternatividad pura, autoorganizada al margen del Estado y del mercado, está muy lejos de ser dominante en la muestra recogida. Parece difícil rehuir por completo el contacto con la Administración y la propiedad privada. Los ingredientes del sistema hegemónico no están ausentes en las PEA, aunque muestren grados distintos de presencia y se concentren en los nodos de contacto entre ambos modelos socioeconómicos. 
Podría decirse, datos en mano, que no solo no existe una dicotomía binaria entre economía alternativa y economía capitalista, sino que la primera está íntimamente vinculada a la segunda, puesto que utiliza algunos de sus recursos y adopta algunas de sus soluciones. Pascual et al. (2018) demuestran que las PEA cubren funciones socioeconómicas desde presupuestos cooperativos: producción de espacio público (huertos comunitarios) y de espacio político (centros sociales autogestionados), intercambio (bancos del tiempo, monedas sociales, mercados de productores) y consumo (grupos de consumo). Argüelles, Anguelovski y Dinnie (2017), Fois (2019) o Nicolosi (2020) han resaltado también la presencia de ingredientes capitalistas en las economías alternativas, con argumentarios de resonancias neoliberales confiados en la iniciativa individual y la autogestión intracomunitaria (y no tanto en las transformaciones estructurales ni en la acción pública) como palancas de transición hacia una sociedad más justa y sostenible: «[...] las economías comunitarias podrían entenderse mejor como híbridos de neoliberalismo y resistencia» (Argüelles et al., 2017: 39).

En suma, cabe afirmar que las PEA no son externas, sino internas al capitalismo como sistema socioeconómico con vocación hegemónica, aunque se ubican en sus bordes e intersticios, como indican las posturas gradualistas ya expuestas. Las comunidades alternativas emplean ciertos recursos del entorno capitalista cercano bajo presupuestos éticos propios para eliminar, transformar o superar ese mismo capitalismo mediante fórmulas diferentes de producción, distribución y consumo (Sánchez, 2019a). La gradación de la alternatividad (tabla 3) no se construye desde fuera del capitalismo, sino desde su mismo interior, añadiendo opciones a las ya existentes y edificándolas con recursos accesibles, aunque infrautilizados. Esta discusión, por tanto, conduce a interpretar dicha gradación (desde las alternativas de adición hasta las de raíz ética) como una función de la presencia relativa de elementos alternativos y convencionales en cada iniciativa concreta. Las tres zonas (profundización, hibridación, transacción) se diferenciarían, entonces, por el hecho de que en cada una de ellas las prácticas económicas alternativas están compuestas por combinaciones específicas de los nueve criterios manejados en esta investigación.

\section{Conclusiones: una lectura geográfica de las economías alternativas}

Este trabajo demuestra que las tipologías de las tablas 1 y 2 no son ejercicios especulativos, sino sistematizaciones de una rica variedad empírica de formas de economía capaces de resolver necesidades sociales. Esa variedad no es binaria ni se pueden delimitar intervalos discretos en su seno. Los datos sugieren, más bien, la existencia de un continuo fluido, poblado por numerosas combinaciones de los criterios de la tabla 5. La metodología aplicada carece de apriorismos teóricos más allá de huir del capitalocentrismo y asumir la existencia real de formas no puramente capitalistas de coordinación económica. Esta metodología se limita a definir un marco donde ubicar dicho continuo, a comparar la empresa convencional con las PEA y a detectar líneas de confluencia y 
divergencia entre estas modalidades de coordinación económica. Se consigue así que sea la metodología - y no tanto la teoría - la que desvele que las alternativas lo son porque recombinan opciones ya existentes bajo el impulso de planteamientos éticos distintivos que, en síntesis, anteponen (de múltiples maneras) la comunidad al individuo, la colaboración a la competencia y la autogestión a la jerarquía.

La escala geográfica ejerce un papel decisivo en la construcción de lo alternativo. La elección deliberada de iniciativas locales perseguía, precisamente, evaluar la capacidad de barrios y ciudades para generar y sostener estos experimentos críticos. Lejos de ser una simple cuenca de aprovisionamiento de recursos materiales, la proximidad geográfica aporta el contexto relacional donde se afianza la confianza interpersonal que sostiene las PEA estudiadas. Comunidad y confianza se dan la mano - casi en sentido literal y, por tanto, en copresencia física - para activar toda una gama de soluciones económicas que encontrarían dificultades para operar a distancia mediante la asamblea, el trueque o las aportaciones voluntarias de los participantes, por ejemplo.

Lo local se perfila como espacio propicio para el lanzamiento de propuestas transformadoras ubicadas en la zona de profundización. Es más, las seis clases de PEA estudiadas tienen como objetivo explícito la recuperación del lugar y el espacio público (huerto, local, plaza, barrio) como contexto preferente de interacción y construcción de una socioeconomía relocalizada.

A partir de ahí, la consolidación en el tiempo y la difusión en el espacio (con la ampliación de su escala de trabajo) y en la sociedad (con la llegada de practicantes no solo culturalmente transformadores, sino también no capitalistas e incluso culturalmente adaptados) empujan a una fracción importante de las PEA a asumir rasgos clasificados como menos alternativos (tabla 5). Su eventual desplazamiento hacia las zonas de hibridación y transacción es consecuencia, bajo la perspectiva gradualista aquí adoptada, de la inserción de las economías alternativas en una sociedad capitalista: sean aditivas, sustitutivas, opositoras, éticas o de desplazamiento, trabajen en el ámbito organizativo, ecológico o social (tabla 3), las PEA deben ganar número o tamaño para extender el espacio alternativo y recortar el espacio económico, social y político dominado por el capitalismo. En esa senda —o en esa pugna—, se registran continuas bifurcaciones y mixturas que alumbran la variedad de actitudes y soluciones expresadas en los análisis teóricos y en los resultados empíricos.

En esta aptitud transformadora de la escala local reside el gran desafío a que se enfrentan las PEA. El entorno inmediato aporta recursos y engendra soluciones alternativas plurales, inclusivas y sostenibles, pero las PEA son reacciones locales a procesos estructurales de enorme dimensión económica, social, política y geográfica. En la literatura especializada, se debate sobre su escalabilidad o capacidad para reforzarse en la zona de hibridación antes de colonizar la zona de transacción sin merma de los valores fundacionales de la zona de profundización. Es un debate cuyo cierre requiere mucha más evidencia empírica y, por ahora, divide a quienes celebran la mera difusión social y geográfica de las PEA y a quienes se resignan a reconocer su fracaso transformador fuera de sus 
nichos originales. Sin embargo, cabe una triple pregunta final: ¿son las nuevas propuestas de Davos, Milanovic, Piketty o Stiglitz una inesperada expresión, en el núcleo del capitalismo, de la influencia — tan difusa como patentede las propuestas alternativas?; ¿están las grandes corporaciones abriéndose a comportamientos y valores emanados de las economías alternativas?; ¿veremos pronto más hibridaciones y mixturas, espoleadas quizá por el impacto inmenso de la COVID-19? Como casi siempre, la respuesta requiere tiempo y, sobre todo, más investigación.

\section{Referencias bibliográficas}

Argüelles, Lucía; Angelovski, Isabelle y Dinnie, Elizabeth (2017). «Power and privilege in alternative civic practices: examining imaginaries of change and embedded rationalities in community economies». Geoforum, 86, 30-41. $<$ https://doi.org/10.1016/j.geoforum.2017.08.013>

Benito del Pozo, Paz y López González, Alejandro (2019). «Urban resilience and the alternative economy: A methodological approach applied to Northern Spain». Geographical Review, 110 (3), 322-340. <https://doi.org/10.1080/00167428.2019.1684195>

Berkeley Roundtable (2019). «Business Roundtable Redefines the Purpose of a Corporation to Promote "An Economy That Serves All Americans"». Recuperado de $<$ https://www.businessroundtable.org/business-roundtable-redefines-the-purposeof-a-corporation-to-promote-an-economy-that-serves-all-americans $>$.

Bresnihan, Patrick y Byrne, Michael (2015). «Escape into the city: everyday practices of commoning and the production of urban space in Dublin». Antipode, 47 (1), 36-54. $<$ http://dx.doi.org/10.1111/anti.12105>

Calle Collado, Ángel; Suriñach Padilla, Rubén y Piñeiro, Conchi (2017). "Comunes y economías para la sostenibilidad de la vida». En: Comunaria. Rebeldías en común. Sobre comunales, nuevos comunes y economías cooperativas. Madrid: Ecologistas en Acción, 15-45.

Caravaca Barroso, Inmaculada y González Romero, Gema (2019). «Una mirada alternativa al desarrollo local. Las monedas sociales en la aglomeración urbana de Sevilla». Scripta Nova. Revista Electrónica de Geografía y Ciencias Sociales, XXIII (621). <https://doi.org/10.1344/sn2019.23.22487>

Chaves, Rafael y Monzón, José Luis (2018). «La economía social ante los paradigmas económicos emergentes: innovación social, economía colaborativa, economía circular, responsabilidad social empresarial, economía del bien común, empresa social y economía solidaria». CIRIEC-España, Revista de Economía Pública, Social y Cooperativa, 93, 5-50. <https://doi.org/10.7203/CIRIEC-E.93.12901>

Climent López, Eugenio y Lardiés Bosque, Raúl (2019). «Los bancos de tiempo y la reproducción de comunidad a escala local». En: SÁnchez Hernández, José Luis (coord.). Espacios y prácticas económicas alternativas en las ciudades españolas. Cizur Menor (Navarra): Thomson-Reuters-Aranzadi, 125-143.

Conill, Joana; CÁrdenas, Amalia; Castells, Manuel; Hlebik, Sviatlana y Servon, Lisa (2012). Otra vida es posible. Prácticas económicas alternativas durante la crisis. Barcelona: Ediciones UOC. 
Cózar Escalante, José Manuel de (2019). El Antropoceno. Tecnología, naturaleza, y condición humana. Madrid: Los Libros de la Catarata.

Espinosa Seguí, Ana (2019). «El papel de los grupos de consumo agroecológico en la construcción de un sistema de distribución y un orden alimentario alternativos». En: Sánchez Hernández, José Luis (coord.). Espacios y prácticas económicas alternativas en las ciudades españolas. Cizur Menor (Navarra): Thomson-ReutersAranzadi, 65-85.

Espinosa Seguí, Ana; Lardiés Bosque, Raúl y Monteserín Abella, Obdulia (2020). «Mercados de productores agroecológicos en España. Venta directa y local en un nuevo escenario de relaciones de consumo». En: Farinós Dasí, Joaquín (coord.); Escribano, Jaime; Peñarrubia, M. a Pilar; Serrano, Javier y Asins, Sabina (eds.). Desafíos y oportunidades de un mundo en transición. Una interpretación desde la Geografía. Valencia: Publicacions Universitat de València, 333-343.

Estefanía, Joaquín (2020). «Refundar el capitalismo (otra vez)». Babelia. Recuperado de <https://elpais.com/cultura/2020/02/28/babelia/1582891433_869353.html>.

Fernàndez, Anna y Miró, Ivan (2016). L'economia social i solidària a Barcelona. Barcelona: La Ciutat Invisible - Ajuntament de Barcelona.

Fors, Francesca (2019). «Enacting Experimental Alternative Spaces». Antipode, 51 (1), 107-128.

<https://doi.org/10.1111/anti.12414>

Fuller, Duncan y Jonas, Andrew E. G. (2003). «Alternative financial spaces». En: Leyshon, Andrew; Lee, Roger y Williams, Colin C. (eds.). Alternative economic spaces. Londres: Sage, 55-73.

Gibson-Graham, Julie-Katherine (2014). «Rethinking the Economy with Thick Description and Weak Theory». Current Anthropology, 55 (9), S147-S153. Recuperado de <https://www.journals.uchicago.edu/doi/pdfplus/10.1086/676646>.

LEE, Roger (2010). «Spiders, bees or architects? Imagination and the radical immanence of alternatives/diversity for political economic geographies». En: Fuller, Duncan; Jonas, Andrew E. G. y LeE, Roger (eds.). Interrogating alterity: alternative economic and political spaces. Farnham: Ashgate, 273-285.

Méndez Gutiérrez del Valle, Ricardo y Monteserín Abella, Obdulia (2019). «Prácticas económicas alternativas en Madrid: una aproximación». En: SÁNCHEZ HeRnández, José Luis (coord.). Espacios y prácticas económicas alternativas en las ciudades españolas. Cizur Menor (Navarra): Thomson-Reuters-Aranzadi, 147-164.

Milanovic, Branko (2020). Capitalismo, nada más. El futuro del sistema que domina el mundo. Barcelona: Taurus.

Moro Gutiérrez, Lourdes y Lamarque, Muriel (2019). "Una metodología multitécnica para el estudio de las prácticas económicas alternativas». En: SÁNCHEZ Hernández, José Luis (coord.). Espacios y prácticas económicas alternativas en las ciudades españolas. Cizur Menor (Navarra): Thomson-Reuters-Aranzadi, 299-307.

Nicolosi, Emily (2020). "Counterspaces against the odds? The production and emancipatory potential of alternative spaces». Geoforum, 108, 59-69. <https://doi.org/10.1016/j.geoforum.2019.11.016>

Pascual Ruiz-Valdepeñas, Henar; Gil Álvarez, Esther y Guerra Velasco, Juan Carlos (2018). "Práctica social, economía alternativa y espacios de proximidad en la ciudad de Valladolid». Recerca. Revista de Pensament i Anàlisi, 23, 193-218. Recuperado de <http://www.e-revistes.uji.es/index.php/recerca/article/ view/2809/2897>.

Piketty, Thomas (2019). Capital e ideología. Barcelona: Planeta. 
Rodríguez Pose, Andrés (2018). «The revenge of the places that don't matter (and what to do about it)». Cambridge Journal of Regions, Economy and Society, 11, 189-219. <https://doi.org/10.1093/cjres/rsx024>

SÁNCHEZ HernánDEZ, José Luis (2019a). "Construir, transformar, superar el capitalismo a través de la acción colectiva localizada: las prácticas económicas alternativas». En: Sánchez HeRnández, José Luis (coord.). Espacios y prácticas económicas alternativas en las ciudades españolas. Cizur Menor (Navarra): Thomson-ReutersAranzadi, 29-62.

- (coord.) (2019b). Espacios y prácticas económicas alternativas en las ciudades españolas. Cizur Menor (Navarra): Thomson Reuters Aranzadi.

Sánchez Hernández, José Luis y Moro Gutiérrez, Lourdes (2019). «Los órdenes de justificación como marco analítico para el estudio de las prácticas económicas alternativas». REIS-Revista Española de Investigaciones Sociológicas, 67, 107-124. <http://dx.doi.org/10.5477/cis/reis.167.107>

Schwab, Klaus (2019a). ¿Qué tipo de capitalismo queremos? Recuperado de <https:// es.weforum.org/agenda/2019/12/que-tipo-de-capitalismo-queremos>.

- (2019b). Manifiesto de Davos 2020: el propósito universal de las empresas en la Cuarta Revolución Industrial. Recuperado de <https://es.weforum.org/agenda/2019/12/ manifiesto-de-davos-2020-el-proposito-universal-de-las-empresas-en-la-cuartarevolucion-industrial/>.

Stiglitz, Joseph (2020). Capitalismo progresista. La respuesta a la era del malestar. Barcelona: Taurus.

STreeck, Wolfang (2017). ¿Cómo terminará el capitalismo? Ensayos sobre un sistema en decadencia. Madrid: Traficantes de Sueños.

Subirats, Joan y García Bernardos, Aurora (eds.) (2015). Innovación social y políticas urbanas en España. Experiencias significativas en las grandes ciudades. Barcelona: Icaria.

SuriÑACH, Rubén (2017). Economías transformadoras de Barcelona. Barcelona: Montaber - Ajuntament de Barcelona.

White, Richard J. (2018). "Reconsiderar radicalmente "lo económico"». En: BBVA Open Mind. La era de la perplejidad. Madrid: Fundación BBVA, 332-355. Recuperado de <https:/www.bbvaopenmind.com/wp-content/uploads/2018/01/ BBVA-OpenMind-La-era-de-la-perplejidad-repensar-el-mundo-que-conociamos. pdf>.

White, Richard J. y Williams, Colin C. (2016). «Beyond capitalocentricism: are non-capitalist work practices "alternatives"?». Area, 48, 325-331. $<$ https://doi.org/10.1111/area.12264>

YATES, Luke (2015). «Everyday politics, social practices and movement networks: daily life in Barcelona's social centres». The British Journal of Sociology, 66, 236-258. <https://doi.org/10.1111/1468-4446.12101> 